\title{
Howard Shevrin - pioneering investigator of psychoanalytic science
}

\begin{abstract}
Jana Steinig*
Department of Psychosomatic Medicine, University of Leipzig, Leipzig, Germany

${ }^{*}$ Correspondence: jana.steinig@medizin.uni-leipzig.de
\end{abstract}

A book review on

Psychoanalytische perspectieven: conversations with Howard Shevrin. His work, his research, his ideas

by Ariane Bazan, Faculteit voor psychologische en pedagogische wetenschappen, 170 pages.

This special issue of the Belgian quarterly "Psychoanalytische Perspectieven" ("Psychoanalytic Perspectives") ${ }^{1}$ offers an excellent portrait of Howard Shevrin one of the most important thinkers and researchers at the interface of psychoanalysis and neurosciences. Hence, this volume is of great relevance for both, psychoanalysts and neuroscientists and at the same time not only recommendable for researchers, but also for clinicians. As I have enjoyed a close collaboration with Shevrin, I truly welcome this rich portrait which gives a very detailed impression of his outstanding achievements.

Guest editor is Ariane Bazan, who is a professor of psychology at the Université Libre des Bruxelles as well as a psychoanalyst. Her special interest in the unconscious processing of language and its association with brain processes (Bazan, 2007, 2011) led to a very close collaboration with Shevrin and his lab. For this reason, she seems particularly qualified for this profound summary of his life and work.

The volume is arranged around three interviews Bazan conducted with Shevrin between 2004 and 2005. They are surrounded by a prefacing chapter of Bazan introducing Shevrin and his co-workers and by a paper Shevrin presented in 2007 called "Unconscious inhibition: brain evidence favoring a psychoanalytic understanding." Accompanied by an introduction of the French psychoanalyst Daniel Wildlöcher, this paper summarizes the most important aspects of Shevrin's research. In addition, there is a French paper from 1972 titled "Condensation and metaphor-The dreaming dreamer and the dreaming creative."

${ }^{1}$ Psychoanalytische Perspectieven is published quarterly at the Department for Psychoanalysis and Clinical Consulting at Ghent University, Belgium - www. psychoanalytischeperspectieven.be
The introductory comments by Bazan and the first interview give an interesting overview of Shevrin's professional career. We learn how he first made contact with psychoanalysis in a military hospital in Oxford where he recovered from an injury he incurred when he was a soldier in Germany during World War 2. Reading Freud's The Interpretation of Dreams from the hospital library he was instantly fascinated and caught by what he read. After he returned to the United States and finished his studies in psychology at the City College of New York and at Cornell University, he received postdoctoral training at the Menninger Foundation and worked with scientists such as Lester Luborsky and Charles Fisher doing mainly subliminal research to study unconscious processes. His first experimental research was directly inspired by The Interpretation of Dreams, as he was able to show that REM-sleep mentation, in which most fanciful and bizarre dreams occur, is dominated by primary process mechanisms which enable the resolution of a subliminally presented rebus stimulus (Shevrin and Fisher, 1967). This work then inspired my own research and I was recently able to replicate Shevrin's early findings with a new (German) rebus (Steinig, 2011). Next to his scientific work, he spent half of his time working clinically and completed psychoanalytic training at the Topeka Institute for Psychoanalysis. In 1973 he joined the University of Michigan as a chief psychologist and opened his own lab. Until today, he is the director of the "Ormond and Hazel Hunt Laboratory for the study of Conscious and Unconscious Processes" at the University of Michigan where he is working with his collaborators Michael Snodgrass, Linda Brakel, and Ramesh Kushwaha.
In the first interview, Shevrin sketches his two main goals which are of profound importance for psychoanalysis since they touch on the fundamental pillars of psychoanalysis: to establish the existence of a psychological unconscious and to investigate the two different modes of mental functioning postulated by Freud primary and secondary process thinking. Reading this volume, it becomes obvious that, impressively, he managed to realize these goals. Moreover, what is exceptional about Shevrin is that he explores those psychoanalytical questions with experimental behavioral and neurophysiological methods. At the same time this research is based on broad clinical experience and is theoretically inspired by the theories of Freud, Rapaport, Rubenstein, and others.

Shevrin and his colleagues were able to provide empirical support for the fundamental proposition of the existence of a psychological unconscious. Interestingly, in his investigation of unconscious processes, Shevrin combined psychoanalytically based hypotheses with neurophysiological measures long before the combination of psychoanalysis and neurosciences was as en vogue as it is today. Already back in 1968 he and Fritzler were the first to record brain responses to subliminal visual stimuli (Shevrin and Fritzler, 1968) and thereby provided strong, objective evidence for the existence of an unconscious. Over the years, Shevrin conducted many subliminal studies using brain responses as objective markers for unconscious processes (Shevrin et al., 1969, 1971; Shevrin, 2001). By this, he and his co-workers were able to provide empirical evidence and specific brain markers for the role of emotional unconscious conflict in social phobias (Shevrin et al., 1992). Summarizing the findings of these stud- 
ies, Shevrin and associates demonstrated that (a) unconscious processes truly exist and are instantiated in the brain. They (b) have cognitive, affective and motivational properties. Furthermore, some of these unconscious processes, particularly dynamic conflictual unconscious processes, are subject to inhibition (c) which is highly individual and can (d) be motivated unconsciously (Shevrin et al., 1996; Snodgrass and Shevrin, 2006).

Furthermore, Shevrin and associates were able to provide empirical evidence for Freud's idea that conscious and unconscious processes follow qualitatively different rules with the primary process being more dominant unconsciously and the secondary process dominating most conscious processes. For instance, they demonstrated that the primary process can be found in REM-sleep mentation (Shevrin and Fisher, 1967), in the thinking of preschool children (Brakel et al., 2002), or in the unconscious thinking of adults (Brakel et al., 2000).

In addition to giving a comprehensive overview about his achievements, this volume offers an inspiring insight into the intellectually stimulating thoughts of Shevrin himself, based on more than half a century of extensive clinical and scientific experiences. For example, he addresses the question about the future of psychoanalysis being challenged by more empirically based sciences and about the on-going debate whether psychoanalysis can be seen as a science or not. He reminds the reader that:

The opposition comes from those (...) who will take position that psychoanalysis has no real evidential base: it's a speculative approach to the human mind, it makes claims that it really can not substantiate and so it can't be taken seriously. They are asking: "Where is the evidence? Where is the systematic research that could support these ideas?” (p. 257).

I am strongly convinced that questions like these ones need to be answered. Especially today, since the decade of the brain produced such a wealth of experimental findings, psychoanalysts are explicitly challenged to underpin the state of psychoanalysis as an empirical science. Therefore, it is particularly welcome that more and more contemporary psychoanalysts follow this challenge and plead for more scientific research within the field of psychoanalysis (Schachter, 2005; Meissner, 2006; Wallerstein, 2009; Chiesa, 2010). The fact that Shevrin devoted his whole scientific career to the search for independent evidence-based support of the fundamental psychoanalytic propositions makes him stand out against most other researchers and makes this special volume about his work, his research and his ideas so definitely worth reading.

\section{REFERENCES}

Bazan,A. (2007). Desfantômes dans la voix. Une hypothèse neuro-psychanalytique sur la structure de l'inconscient. Montreal: Editions Liber.

Bazan, A. (2011). Phantoms in the voice: a neuropsychoanalytic hypothesis on the structure of the unconscious. Neuropsychoanalysis 13, 161-176.

Brakel, L., Kleinsorge, S., Snodgrass, M., and Shevrin, H. (2000). The primary process and the unconscious: experimental evidence supporting two psychoanalytic presuppositions. Int. J. Psychoanal. 81, 553-569.

Brakel, L., Shevrin, H., and Klein Villa, K. (2002). The priority of primary process categorizing: experimental evidence supporting a psychoanalytic developmental hypothesis. J. Am. Psychoanal. Assoc. 50, 483-505.

Chiesa, M. (2010). Research and psychoanalysis - still time to bridge the great divide? Psychoanal. Psychol. 27, 99-114.

Meissner, W. (2006). Prospects for psychoanalysis in the 21st century. Psychoanal. Psychol. 23, 239-256.
Schachter, J. (2005). Contemporary American psychoanalysis: a profession? Increasing the role of research in psychoanalysis. Psychoanal. Psychol. 22, 473-492.

Shevrin, H. (2001). Event-related markers of unconscious processes. Int. J. Psychophysiol. 42, 209-218.

Shevrin, H., Bond, J., Brakel, L., Hertel, R., and Williams, W. (1996). Conscious and Unconscious Processes: Psychodynamic, Cognitive, and Neuro-physiologic Convergences. New York: Guilford Press.

Shevrin, H., and Fisher, C. (1967). Changes in the effects of a waking subliminal stimulus as a function of dreaming and nondreaming sleep. J. Abnorm. Soc. Psychol. 72, 362-368.

Shevrin, H., and Fritzler, D. (1968). Visual evoked response correlated of unconscious mental processes. Science 161, 295-298.

Shevrin, H., Smith, W., and Fritzler, D. (1969). Repressiveness as a factor in the subliminal activation of brain and verbal responses. J. Nerv. Ment. Dis. 149, 261-269.

Shevrin, H., Smith, W., and Fritzler, D. (1971). Average evoked response and verbal correlates of unconscious mental processes. Psychophysiology 6, 149-162.

Shevrin, H., Williams, W., Marshall, R., Hertel, R., Bond, J., and Brakel, L. (1992). Eventrelated potential indicators of the dynamic unconscious. Conscious. Cogn. 1, 340-366.

Snodgrass, M., and Shevrin, H. (2006). Unconscious inhibition and facilitation at the objective detection threshold: replicable and qualitatively different unconscious effects. Cognition 101, 43-79.

Steinig, J. (2011). Primary and Secondary Processing of a Waking Subliminal Stimulus in REM-and Non-REMsleep - Empirical Investigation of a Psychoanalytic Concept. Doctoral dissertation, Available at: http:// nbn-resolving.de/urn:nbn:de:gbv:46-00102441-12

Wallerstein, R. (2009). What kind of research in psychoanalytic science? Int. J. Psychoanal. 90, 109-133.

Received: 01 May 2012; accepted: 07 May 2012; published online: 15 June 2012.

Citation: Steinig J (2012) Howard Shevrin - pioneering investigator of psychoanalytic science. Front. Psychology 3:163. doi: 10.3389/fpsyg.2012.00163

This article was submitted to Frontiers in Psychoanalysis and Neuropsychoanalysis, a specialty of Frontiers in Psychology.

Copyright (C) 2012 Steinig. This is an open-access article distributed under the terms of the Creative Commons Attribution Non Commercial License, which permits noncommercial use, distribution, and reproduction in other forums, provided the original authors and source are credited. 